\title{
Anotações sobre o Tristão no Fauno: dois prelúdios ao pós-tonal.
}

\author{
Acácio Tadeu de Camargo Piedade (UDESC)
}

Resumo: A proposta deste artigo é comentar uma homologia estrutural que se dá nos primeiros compassos de duas obras fundamentais da história da música européia: o prelúdio da ópera Tristan und Isolde, de Richard Wagner, e o Prélude à l'après-midi d'un faune, de Claude Debussy. Inicialmente, uma breve discussão sobre o chamado acorde "tristão" conduz a uma apresentação da referida homologia, após o que seguem comentários e discussões. O objetivo não é apresentar uma nova interpretação do acorde "tristão", mas sim comentar, sob o ponto de vista de uma musicologia que absorve ou é absorvida pela análise, o diálogo entre as obras elas mesmas e sua forma furtiva para a análise, porém constitutiva na história da música.

Palavras-chave: Acorde Tristão; Wagner; Debussy; Análise Musical.

Abstract: This article comments a structural homology which appears in the beginnings of two masterpieces of European music history: Wagner's prelude to Tristan und Isolde, and Debussy's Prélude à l'après-midi d'un faune. After a brief discussion on the so-called "tristan" chord, the homology is presented and commented. Under the perspective of a musicology which absorbes or is absorbed by analysis, this article aims not to present a new interpretation of the "tristan" chord, but to discuss the dialog between the musical pieces themselves and its furtive nature for analysis, but which is constitutive to music history.

Keywords: Tristan chord; Wagner; Debussy; Musical Analysis.

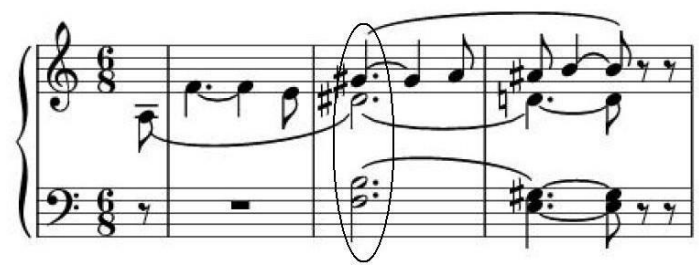

[exemplo 1 - o acorde "tristão"]

Desde a primeira audição da ópera Tristan und Isolde, de Richard Wagner, em 1865, muito já foi escrito sobre o chamado acorde "tristão" (ex. 1), incitando fartos debates entre teóricos e analistas. A sonoridade meio-diminuta, apresentada desta forma destacada, no coração de uma peça tão importante, foi encarada inicialmente como resultante de seu aspecto funcional. Formado pelos intervalos de trítono, $\mathbf{3}^{\mathbf{a}}$ maior e 4⿳亠丷a , o acorde, que antecede uma dominante, foi interpretado como variante da função sub-dominante ${ }^{1}$, ou como segundo grau alterado ${ }^{2}$, ou dominante da dominante ${ }^{3}$. Para vários analistas, a nota Sol ${ }^{\#}$ foi interpretada como sendo uma apojatura daquela que seria a verdadeira nota de acorde, o Lá, e por isto o acorde "tristão" seria tributário de um acorde de segundo grau com sexta aumentada, a

\footnotetext{
${ }^{1}$ LORENZ (1985), entre outros.

${ }^{2}$ H, para SCHOENBERG (2006, p. 100-101).

${ }^{3}$ KURTH (1985), entre outros.
} 
chamada sexta "francesa" ${ }^{4}$. Veja-se o exemplo abaixo, onde as apojaturas aparecem como notas negras e a tonalidade é considerada Lá menor:

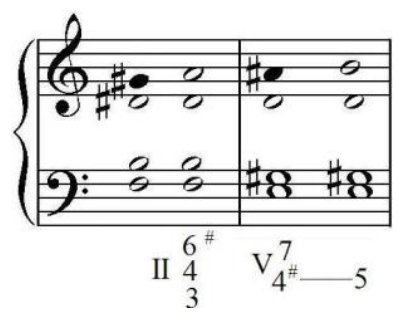

[exemplo 2 - o acorde "tristão" como sexta francesa]

Estas interpretações foram contestadas por vários comentadores, como BAILEY, que afirma que Wagner se esforçou para que o ouvinte percebesse o Sol ${ }^{\#}$ como nota de acorde (1985, p. 124). Assim, o Sol\# seria uma nota de acorde e o Lá uma nota de passagem. Em sua análise do Tristan, MITCHELL (1985, p. 247-8) mostra, com vários argumentos, levando em conta outras aparições do acorde "tristão" na peça, que esta acepção seria a mais correta ${ }^{5}$. Em direção a uma perspectiva mais flexível, podemos partir de Schoenberg, que o considerou um acorde vagante ${ }^{6}$ e que, assim, pode suceder qualquer outro acorde, sua função tonal dependendo do contexto ${ }^{7}$. Nesta direção, interessa entender o acorde "tristão" como meio-diminuto, ou seja, enarmonicamente equivalente ao meio-diminuto. Aparentemente Wagner tinha este objetivo, a julgar pelas enarmonias empregadas na versão para piano e vocal elaborada por Hans von Bülow, aprovada por Wagner ${ }^{8}$.

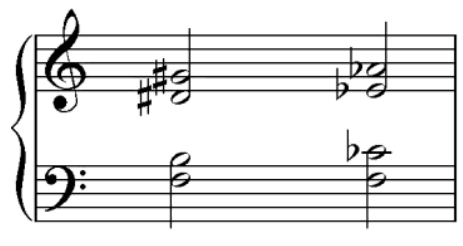

tristão original versão de Bülow

[exemplo 3 - enarmonia do acorde "tristão" na versão de Bülow]

O acorde "tristão", enquanto meio-diminuto, pode ser entendido também como inversão de uma tríade menor com sexta adicionada (no caso acima, Láb

\footnotetext{
${ }^{4}$ Como SESSIONS (1985) ou SALZER (1962:176), entre outros. PISTON (1994, p. $\left.363-4\right)$ apresenta o acorde como meio-diminuto oriundo de $\mathrm{II}^{7}$ do modo menor, porém que pode ser reinterpretado como acorde de sexta francesa.

${ }^{5}$ Ver mais sobre este debate em NATTIEZ (1984). Ver uma discussão sobre este acorde em MENEZES (2002:80), onde é tratado como início de uma cadência frigia.

${ }^{6}$ Cf. SCHOENBERG (1999, p.367).

${ }^{7}$ Ver DUDEQUE (1997).

${ }^{8}$ Cf. KURTH (1985, p. 194-5).
} 
menor) ${ }^{9}$. A aparente despreocupação de Wagner quanto aos nomes das notas e, portanto, sua função no acorde, leva a crer que ele estava mais interessado no acorde "tristão" como sonoridade. Importa ressaltar aqui este desvio de foco: do papel tonal do acorde, onde desempenharia uma função secundária, rumo à experiência de sua sonoridade em primeiro plano, sua feição sonora para além da funcionalidade. Ou seja, interessa descrevê-lo como uma espécie de entidade harmônica ${ }^{10}$ que constitui a essência do que poderíamos chamar de "idioma meio-diminuto", linguagem fartamente empregada das últimas décadas do século XIX até as primeiras décadas do $X X$, peça fundamental dos movimentos chamados "impressionista" e "expressionista". $\mathrm{O}$ uso do meio-diminuto, neste período, vai além de sua função básica de $1 \mathrm{I}^{7}$ do modo menor, servindo como conexão entre acordes gerada por passo ou nota comum, ou ainda, de forma mais livre, como dissonância "emancipada" ${ }^{11}$.

Entretanto, minha intenção neste artigo não é fundamentar este idioma ou apresentar uma nova interpretação do acorde "tristão", mas comentar, sob o ponto de vista de uma musicologia que absorve ou é absorvida pela análise ${ }^{12}$, uma homologia estrutural que se dá nos primeiros compassos de duas obras fundamentais: o prelúdio da ópera Tristão e Isolda, de Richard Wagner (doravante Tristan) e o Prélude à l'aprèsmidi d'un faune, de Claude Debussy (doravante Prélude). Com isto, pretendo chamar a atenção sobre certas formas de diálogo entre as obras musicais elas mesmas, fenômeno que, muitas vezes de forma furtiva à análise, norteia a construção da história da música. De início, farei comentários sobre estas duas obras e aspectos contextuais, destacando a influência wagneriana em Debussy. Em seguida, através de exemplos musicais e diagramas, apresentarei a homologia estrutural, após o que tecerei comentários finais.

Mas afinal, o que mais há para se falar sobre Tristan e Prélude? De fato, estas duas obras, separadamente, são tratadas em uma vastíssima literatura, ambas tendo sido ali extensamente analisadas e comentadas. A ópera Tristan und Isolde estreou em 1865, em Munique, sob a regência de Hans von Bülow, amigo e admirador de Wagner, que já havia estreado o prelúdio, em Praga, em 1859. A repercussão foi grande, houve muito debate no meio musical alemão, acalorado pela idéia wagneriana de "música do futuro" ${ }^{13}$. A linguagem de Tristão e Isolda trazia mudanças importantes no vocabulário harmônico do século XIX tais como, por exemplo, a mistura modal, a precedência do aspecto linear na condução harmônica dada pelo cromatismo, a erosão da função dominante através da adição de resoluções alternativas, o acorde $V^{7}$ como consonância local temporária, a exposição indireta de elementos temáticos e motívicos, entre outras ${ }^{14}$. Cabe lembrar que Wagner inspirou-se em Liszt e, certamente, em Beethoven, como se deduz da análise da sonata para piano Op. $31 \mathrm{Nr}$.

\footnotetext{
${ }^{9}$ Ver BAILEY (1985, p. 123).

${ }^{10}$ Ver MENEZES (2006, p. 45).

${ }^{11}$ Ver SIMMS (1996, p. 45-46), onde há exemplos destes usos do "tristão" em Fauré e Schoenberg.

${ }^{12}$ COOK \& EVERIST (2001, p. xvii)

${ }^{13}$ Sobre a repercussão de Tristão, ver BAILEY (1985, p. 12-35). Wagner escreveu o artigo Zukunftsmusik em 1860.

${ }^{14}$ Ver o estudo analítico de BAILEY sobre os rascunhos e versões preliminares de Tristão e Isolda (1985, p. 113-146).
}

SIMPÓSIO DE PESQUISA EM MÚSICA 2007 - DEARTES/UFPR

DAPesquisa, Florianópolis, v.3 n.5, p.735-750, 2008. 
3 a partir do compasso 35, trecho que envolve o acorde "tristão" avant la lettre em uma textura e posições específicas, como repetição oitavada.

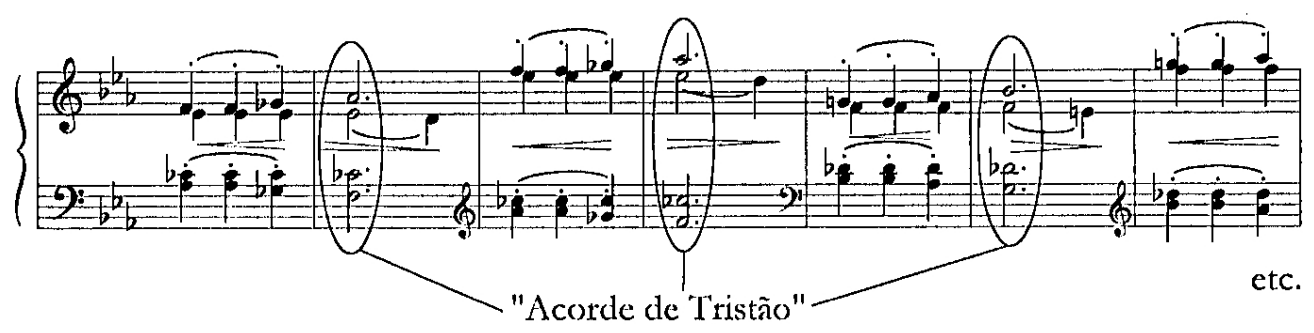

[exemplo 4: o acorde "tristão" em Beethoven. Exemplo extraído de MENEZES, 2002, p.82]

Vemos no exemplo 3 este conhecido caso da literatura analítica, o trecho do c. 35 a 41 desta sonata, onde o acorde tristão se transforma em diminuto. Trata-se de um trecho modulante que vai de I ( $\mathrm{Mi}^{\mathrm{b}}$ maior), tonalidade principal, para $\mathrm{V}\left(\mathrm{Si}^{\mathrm{b}}\right.$ maior, atingido no c.46), no qual Beethoven emprega o acorde "tristão" como VII sensível de tonalidades intermediárias por ele tonicizadas. Como fica claro, dado o contexto tonal da peça, que há apojaturas aqui, na voz do contralto ( $\mathrm{Mi}^{\mathrm{b}}$ - Ré no primeiro exemplo), pode-se dizer que Beethoven, apesar de usar o acorde de forma destacada e em tempo forte, ainda não fez uso do potencial múltiplo da sonoridade "tristão", o que, a meu ver, somente ocorrerá em Wagner. Mas uma homologia estrutural em relação a Tristan chama a atenção: como no trecho inicial desta última, a estrutura (aqui de 2 compassos, lá de 3) é transposta (aqui, um tom acima, lá, uma terça menor acima), sendo seguida de repetição oitava acima (lá, na terceira repetição, cc. 10-13). Enfim, este pequeno trecho de Beethoven certamente iluminou a criatividade de Wagner e, de uma forma sutil, continua presente no Tristão. Este é um dos vários exemplos possíveis de uso de acorde meio-diminuto antes de Wagner. A sonoridade "tristão" nasce, assim, da musicalidade germânica romântica e pós-romântica, do espírito do século XIX, irmanada à dissolução da funcionalidade harmônica tonal, que com ela se acentua.

A música de Wagner, parte fundamental deste movimento, era muito apreciada em Paris pelos artistas e intelectuais. Após o fracasso da montagem de Tannhäuser nesta cidade, em 1861, Baudelaire escreveu uma inspirada carta a Wagner, dizendo-lhe que, com sua música, "on se sent tout de suite enlevé et subjugué", e que "ces profondes harmonies me paraissaient ressembler à ces excitants qui accélerent le pouls de l'imagination" ${ }^{15}$. Estas palavras do grande poeta revelam efeitos da música wagneriana nos artistas parisienses dos anos 60, particularmente entre os poetas simbolistas. Em 1885, o poeta Mallarmé, que era amigo de Debussy, escreveu um ensaio intitulado Richard Wagner, rêverie d'un poete français na Revue Wagnérienne, mostrando o alcance da estética wagneriana na linguagem poética ${ }^{16}$. Até a virada do século XX, os artistas parisienses desenvolveram importantes

\footnotetext{
15 "Sente-se de imediato elevado e subjugado"; "estas harmonias profundas me parecem se assemelhar aos estimulantes que aceleram o pulso da imaginação". BAUDELAIRE (1977, p. 51-52). Ver NATTIEZ (2005, p. 213-227).

${ }^{16}$ AUSTIN (1970, p. 3).
} 
movimentos, como a pintura impressionista e a poesia simbolista, que surgiram em reação às sólidas convenções realistas do início do século XIX, em prol de uma nova arte para um novo século. A música francesa, entretanto, não acompanhava este passo, mantendo-se "elevada e subjugada" pela musicalidade wagneriana, predominando tipos formais e uma estética germânica ${ }^{17}$.

A primeira apresentação do prelúdio de Tristão e Isolda em Paris (versão concerto), em 1860, teve boa repercussão do público, apesar de algumas críticas negativas, especialmente de Berlioz ${ }^{18}$. A primeira apresentação da ópera completa ocorreu apenas em 1899, regida pelo famoso maestro Charles Lamoureux, amante e divulgador da obra wagneriana. A crítica musical da virada do século tomou esta apresentação como um marco da evolução da arte musical ${ }^{19}$.

Neste ambiente, a formação da Société Nationale de Musique, em 1871, foi um esforço de construir um "renascimento" musical baseado na herança do passado musical francês, onde a extensão do cromatismo e a intensificação expressiva tipicamente germânicas dessem lugar a uma musicalidade de temperamento mais francês ${ }^{20}$. Debussy desponta neste momento e lidera este esforço já em suas primeiras obras.

Debussy não apenas apreciava a música de Wagner: ele tocava a obra de Wagner, ao piano, em diversos locais parisienses ${ }^{21}$. Não escapou, portanto, da "febre wagneriana", e mantinha consigo a partitura do Tristão e Isolda ${ }^{22}$. Em 1889, fez duas peregrinações a Bayreuth, onde ouviu esta ópera. Era profundamente influenciado pela música de Wagner, o que se pode notar especialmente no Pelléas, fato fartamente comentado por um crítico musical da época, o norte-americano Lawrence Gilman $^{23}$. Em canções da década de 90, como Cinq Poèmes de Baudelaire, também é clara a influência de Wagner. De fato, a música wagneriana parece irmanada e perfeitamente adequada ao espírito do simbolismo poético, contrário ao naturalismo, por sua entrega à imaginação interior e aos estados de alma, ao sensual e ao sombrio ${ }^{24}$.

Debussy tinha para com Wagner, entretanto, sentimentos ambíguos, pois ao mesmo tempo em admirava sua música, procurou deliberadamente afastar-se desta influência, que julgava nociva para o desenvolvimento de sua própria linguagem ${ }^{25}$. Este desejo revela a profunda importância do pensamento musical wagneriano para Debussy, isto não apenas no sentido harmônico, mas também no naturalismo

\footnotetext{
${ }^{17}$ MORGAN (1991, p.40).

${ }^{18}$ BAILEY (1985) p. 28.32.

${ }^{19}$ Cf. GILMAN (1907). Sobre o wagnerismo na vida musical parisiense do século XIX, ver ainda GUINCHARD (1963).

${ }^{20}$ MORGAN (1991, p. 40-41)

${ }^{21}$ LEROLLE (1992).

${ }^{22}$ BONNEUR (1992).

${ }^{23}$ GILMAN (1907).

${ }^{24}$ Ver FURNESS (1995).

${ }^{25}$ Debussy afirmou a Ernest Hébert, em 1887, que o primeiro ato de Tristão e Isolda era definitivamente a coisa mais bonita que conhecia em termos de profundidade emocional (KELLY, 2003, p. 32).
} 
relacionado à expressividade lingüística e no fluxo dramático das emoções ${ }^{26}$. Estou me referindo aqui especificamente ao wagnerismo no Debussy da "primeira fase", antes daquilo que seu amigo, o crítico Louis Laloy, chamou de sua nouvelle manière, o que se deu a partir de La Mer, quando Debussy se voltou para as sonoridades orientais e ibéricas ${ }^{27}$. Note-se, entretanto, que a admiração pela música wagneriana deixou rastros importantes em toda a carreira de Debussy ${ }^{28}$. Basta ver a quantidade de referências a Wagner, tanto de amor quanto de ódio, presentes nos seus escritos ${ }^{29}$.

Debussy não era somente um compositor "intuitivo", um improvisador, pintor de imagens musicais: era igualmente o construtor de estruturas que, sabia, eram inovadoras. Minucioso quanto às proporções, este compositor chegou a utilizar a seção áurea, séries matemáticas e padrões geométricos na construção da estrutura de diversas de suas obras ${ }^{30}$. Na própria estrutura musical do Prélude pode estar ancorada, como uma resposta formal no nível do timbre, a estrutura poética do poema L'Aprèsmidi d'um faune, de Mallarmé ${ }^{31}$. Nesta direção, entendo que, para além das paródias evidentes $^{32}$, faz parte da linguagem de Debussy a utilização, de forma sutil, de referências e homologias em diversos níveis estruturais e semânticos. É neste sentido que a homologia que comentarei adiante pode ser pertinente. Apesar do fato que, antes do Prélude, o acorde "tristão" já havia sido largamente utilizado por Debussy na sua ópera Pélleas et Mélisande ${ }^{33}$, a configuração estrutural que mostrarei não havia aparecido antes em sua música. Nestes primeiros compassos, dois prelúdios se tocam, abrindo um novo tempo, aquele do pós-tonal. Retomarei este ponto no final deste artigo.

A homologia estrutural ${ }^{34}$ é a seguinte: nos primeiros compassos de Tristan, uma linha de violoncelo iniciada por salto ascendente de sexta menor que, descendo cromaticamente, conduz ao acorde "tristão", apresentado pelas madeiras, sendo este conduzido por cromatismo a um acorde de dominante, Mi com 7ạ, seguido de pausa.

\footnotetext{
${ }^{26}$ MORGAN (1991, p. 43).

${ }^{27}$ BROWN (2003)

${ }^{28}$ Para HOLLOWAY (1979), o wagnerismo de Debussy é muito mais profundo do que se imagina, encontrando sua mais forte expressão em Jeux.

${ }^{29}$ Ver DEBUSSY (1989 [1921]).

${ }^{30}$ HOWAT (1983).

${ }^{31}$ Cf. CODE (2001), que argumenta que Debussy compôs uma "fuga literária”.

${ }^{32}$ Como na peça VI da Children's Córner Suite, Golliwogg's cake walk, onde, a partir do c. 61, o primeiro motivo do Tristão e Isolda aparece várias vezes sob uma roupagem totalmente diferente. Note-se que o acorde "tristão" não é utilizado, em seu lugar aparecendo uma inversão de Ré bemol dominante com quarta e nona, na primeira vez, e na segunda um Sol bemol maior com sexta adicionada, como tônica. É bem clara a ironia deste Tristão e Isolda em ragtime, que parece não conseguir mais que uma simples cadência V-I. Ver BAUER (1992).

${ }^{33}$ Ver SMITH (1989), que trata este acorde como meio-diminuto e afirma que a linguagem meiodiminuta debussyana é um meio de expressar o páthos de profunda tristeza (:99-101). Para outras homologias entre Prélude e Tristão, ver também ABBATE (1981).

${ }^{34}$ Entendo por homologia estrutural uma semelhança não-superficial de estrutura entre obras musicais, abrangendo aspectos como padrão harmônico, instrumentação, textura, ritmo, segmentação formal, etc.
} 


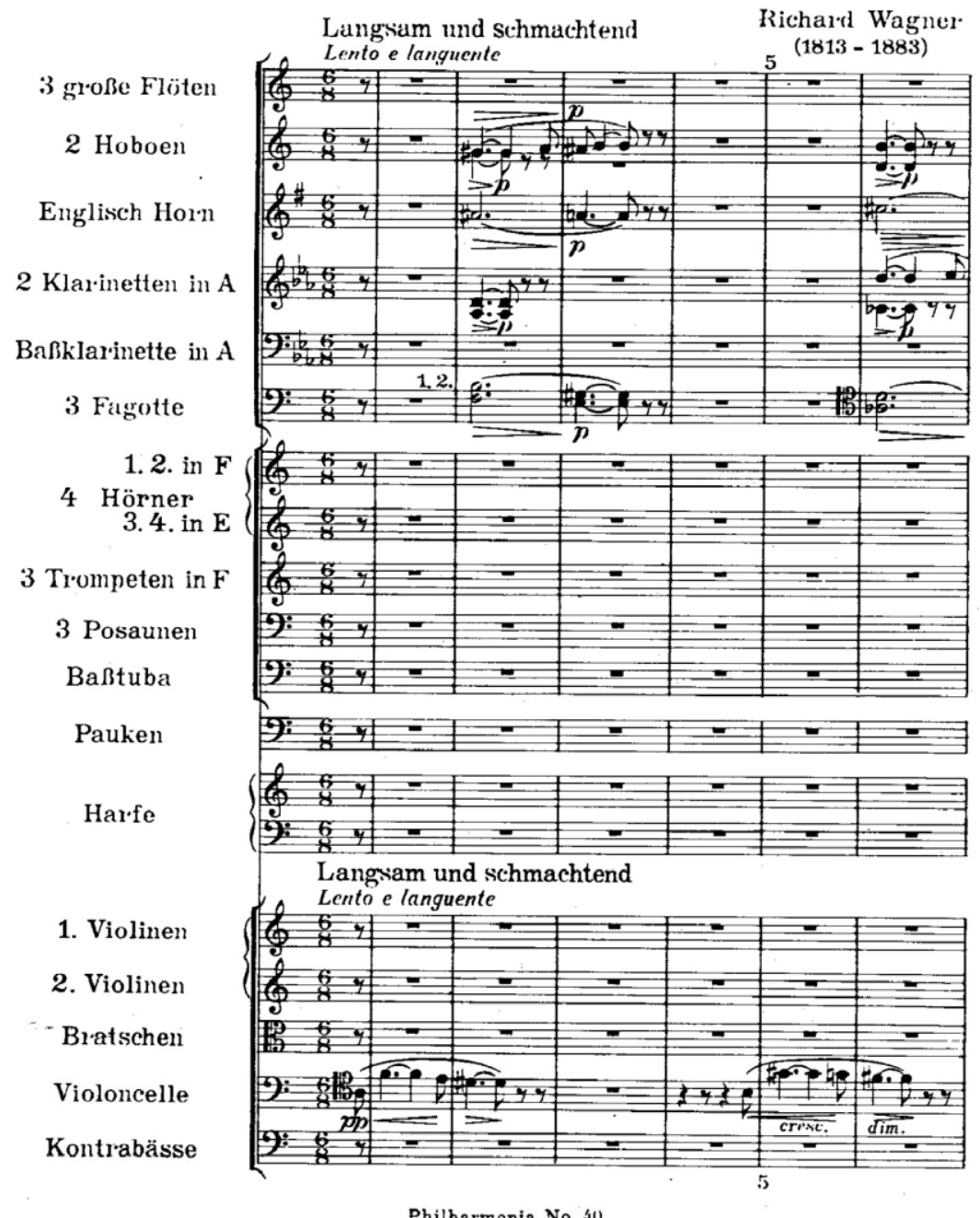




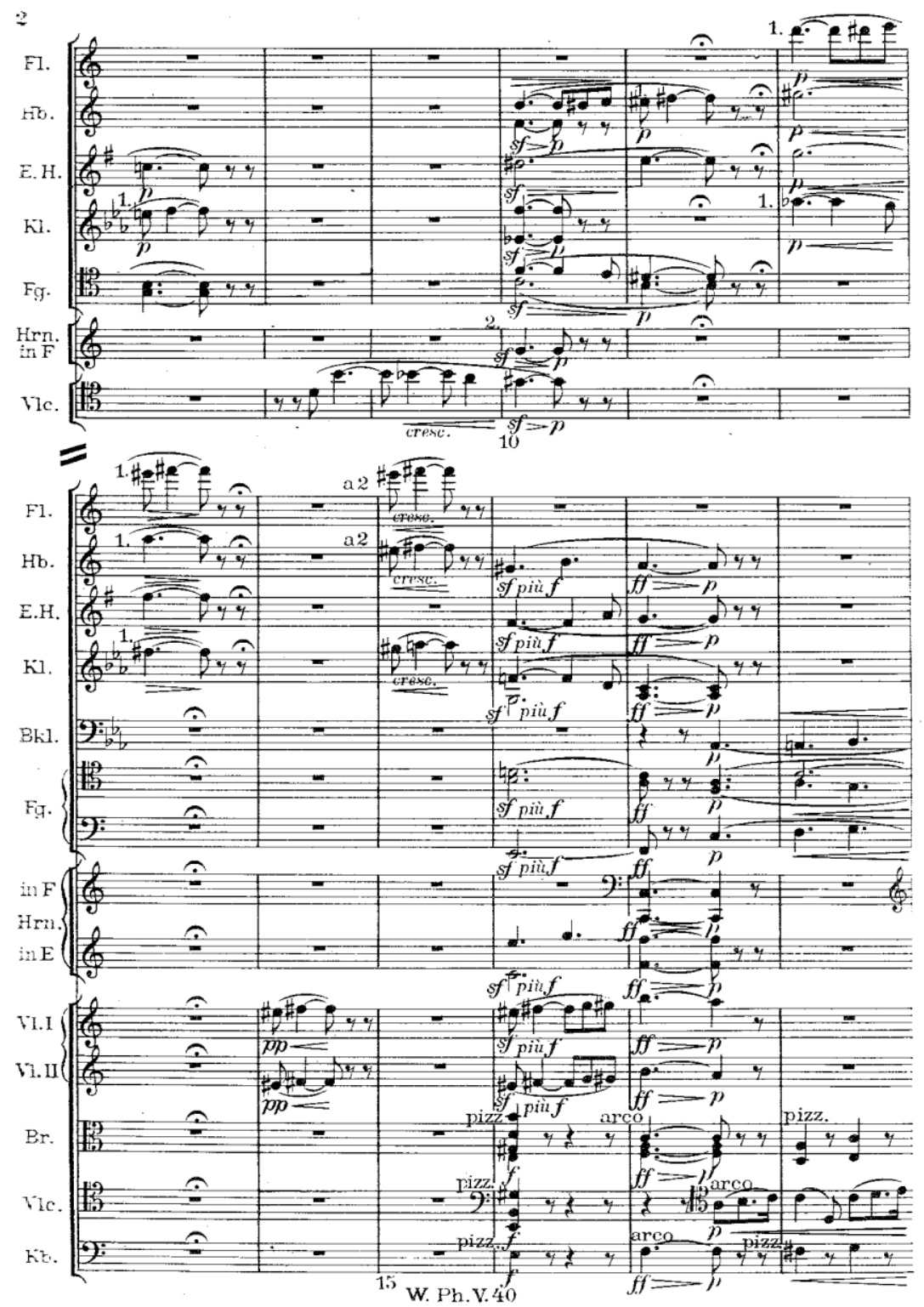

[exemplo 5- início do Prelúdio de Tristão e Isolda] ${ }^{35}$

Esta idéia se repete três vezes. Após a longa pausa de sete tempos, a configuração se repete com salto de sexta maior e acorde "tristão" nas madeiras transposto uma terça menor acima, levando à dominante Sol com 7ạ. Nova pausa de quatro tempos, e mais uma vez a configuração se apresenta: salto de sexta maior nos violoncelos, cromatismo, acorde "tristão", cromatismo, dominante (Si com 7ạ). Aparecem então duas vezes as notas $\mathrm{Mi}^{\#}$ e Fá", na terceira vez soando sobre o acorde de Mi com 7ạ, que resolve em um grande Fá maior.

\footnotetext{
${ }^{35}$ Partitura de bolso, edição Philharmonia/Universal Ed., Viena.
} 
Já o Prélude se abre com uma linha melódica em arabesco, um solo de flauta, que conduz a um acorde no c.3, nas madeiras, trompas e harpa, que tem as características de acorde "tristão" (um Dó\# menor com sexta adicionada, ou Lá ${ }^{\#}$ meiodiminuto na primeira inversão). Segue a este acorde um acorde de dominante ( $\mathrm{Si}^{\mathrm{b}} \mathrm{com}$ 7ạ), após o qual há uma pausa. A seqüência harmônica "tristão-dominante" é repetida, seguindo-se uma repetição apenas do $\mathrm{Si}^{\mathrm{b}}$.

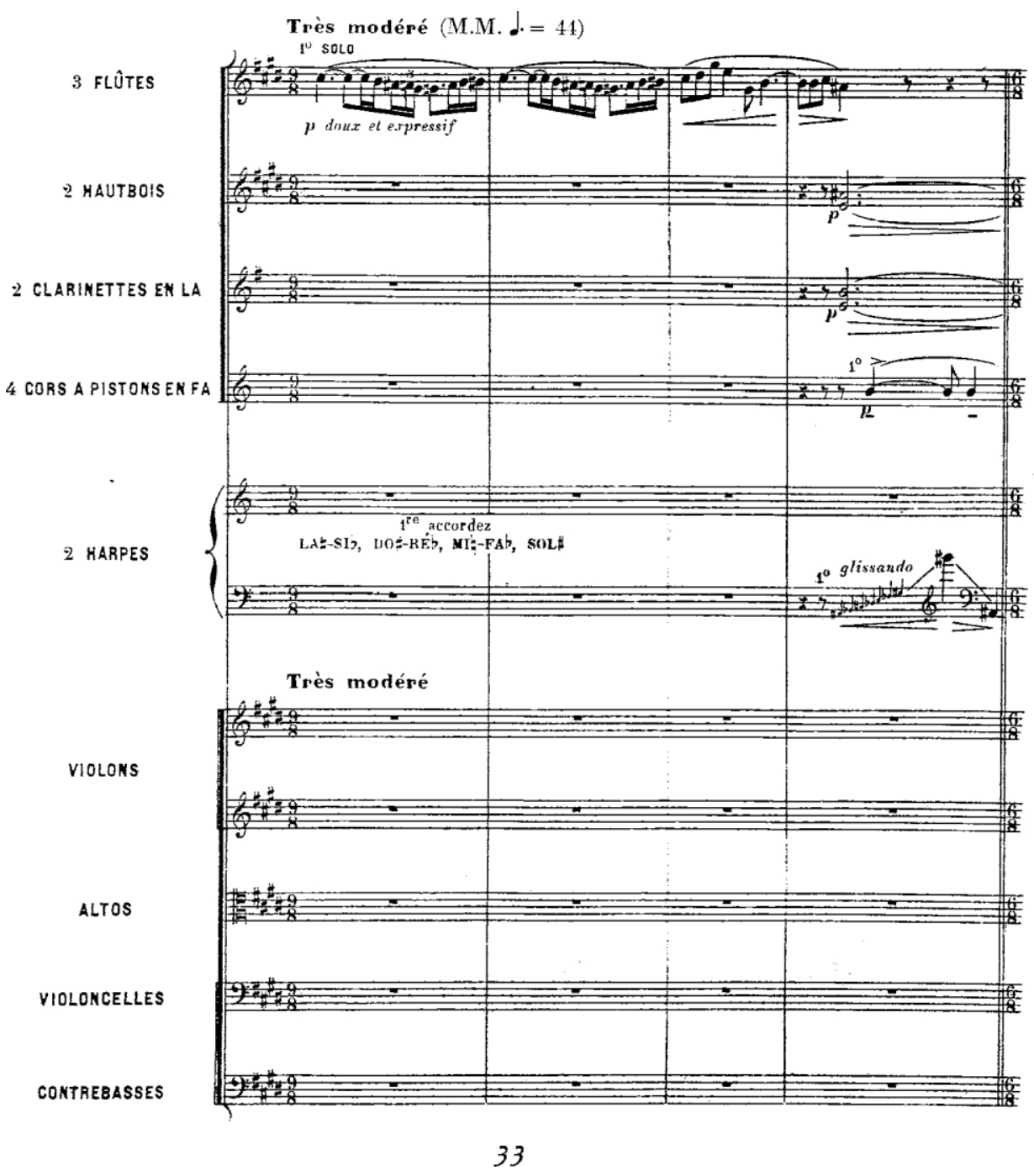


(5)

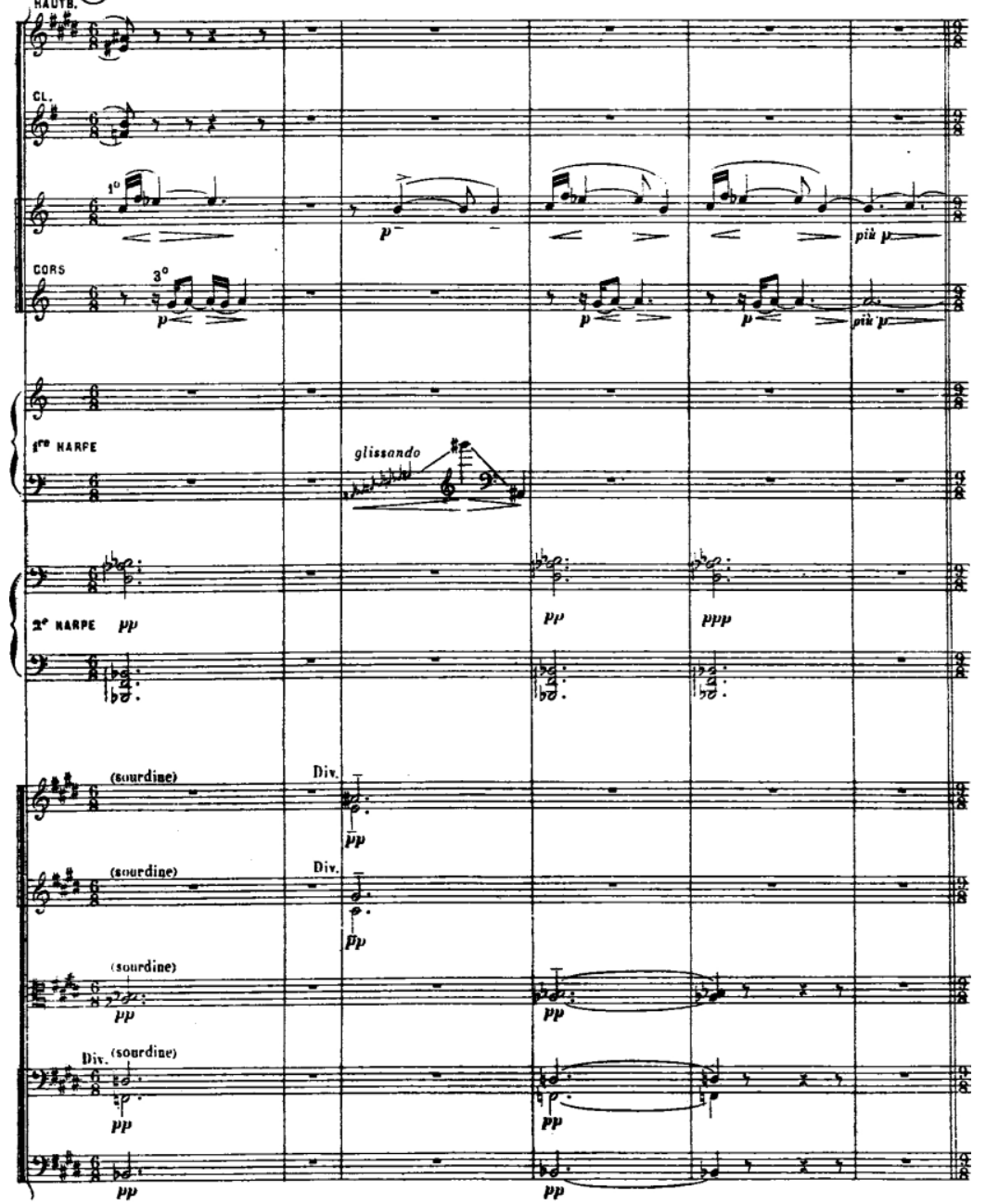

[exemplo 6 - início do Prélude à l'après-midi d'um faune] ${ }^{36}$

É importante lembrar que a repetição imediata de uma estrutura, ou duplicação, é um elemento extremamente importante no estilo de Debussy ${ }^{37}$. Há duas duplicações aqui: uma da própria estrutura tristão-dominante (c.4-5 e 7-8), e outra que duplica apenas a dominante (8-9). Note-se que nesta segunda duplicação, a primeira trompa toca a nota $\mathrm{mi}$, correspondente ao quarto grau elevado de $\mathrm{Si}^{\mathrm{b}}$ (última nota dos c. 8 e 9$)$.

Assim, há no Prélude a mesma estrutura (acorde "tristão" - dominante com 4ạ aumentada resolvendo na $5^{\text {a }}$ ) que se encontra no Tristan. A homologia completa, portanto, envolve todos estes aspectos. Veja-se o diagrama abaixo, com reduções para piano: acima, o Tristan, abaixo, o Prélude.

\footnotetext{
${ }^{36}$ Partitura em AUSTIN (1970).

${ }^{37}$ Ver RUWET (1972).

SIMPÓSIO DE PESQUISA EM MÚSICA 2007 - DEARTES/UFPR
} 


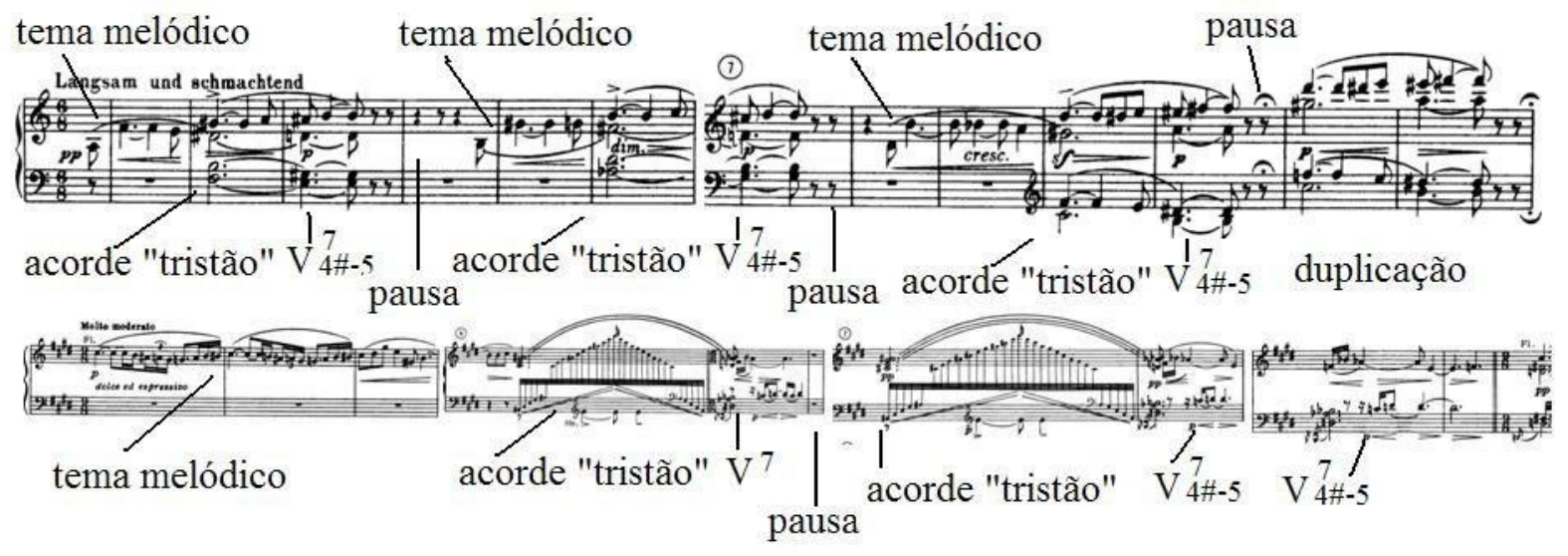

[exemplo 7 - comparação dos primeiros compassos de Tristan e Prélude]

Este diagrama mostra a homologia grosso modo. Um detalhe interessante é que a voz mais grave do acorde "tristão" em Tristan resolve meio tom abaixo, na fundamental da dominante, enquanto as vozes intermediárias descem e o soprano sobe, realizando o leitmotiv cromático. Na relação "tristão-dominante" há, assim, uma distância de semitom no baixo. Já no Prélude, é o próprio acorde "tristão" que se transforma em dominante: através da enarmonia, o baixo e o soprano se mantêm,

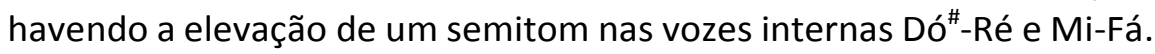

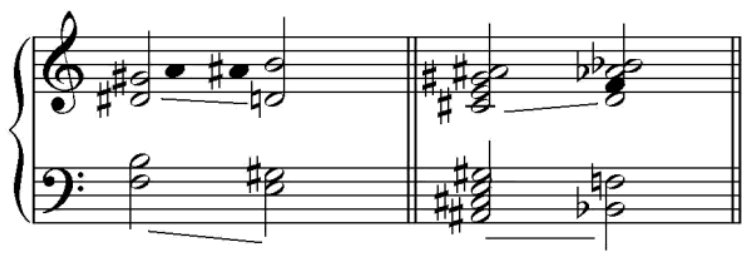

[exemplo 8 - transformações "tristão-dominante"]

Gostaria de mostrar ainda uma outra homologia estrutural que se pode observar: o uso específico do acorde "tristão" nos 3 últimos compassos do Prélude e no final de Tristão e Isolda, na seção chamada de Liebestod, nos últimos 5 compassos da ópera.

Neste final da ópera Tristão, com o mais elevado grau de expressividade, surge o motivo cromático ascendente da abertura, conhecido como o leitmotiv do amor ou desejo ( $5 \mathrm{c}$. antes do fim). O oboé e o corne inglês dobram o motivo, as cordas, em trêmolo, e os trombones, tocam o acorde "tristão": uma segunda inversão do quarto grau com sétima e fundamental aumentada de Si maior (Si, Fá, Ré\# e Sol\#, 
configurando a sonoridade de Fá meio-diminuto) levando à subdominante Mi menor, seguida de primeira inversão do segundo grau (outra configuração "tristão"), e chegando à grande tônica final, Si maior.

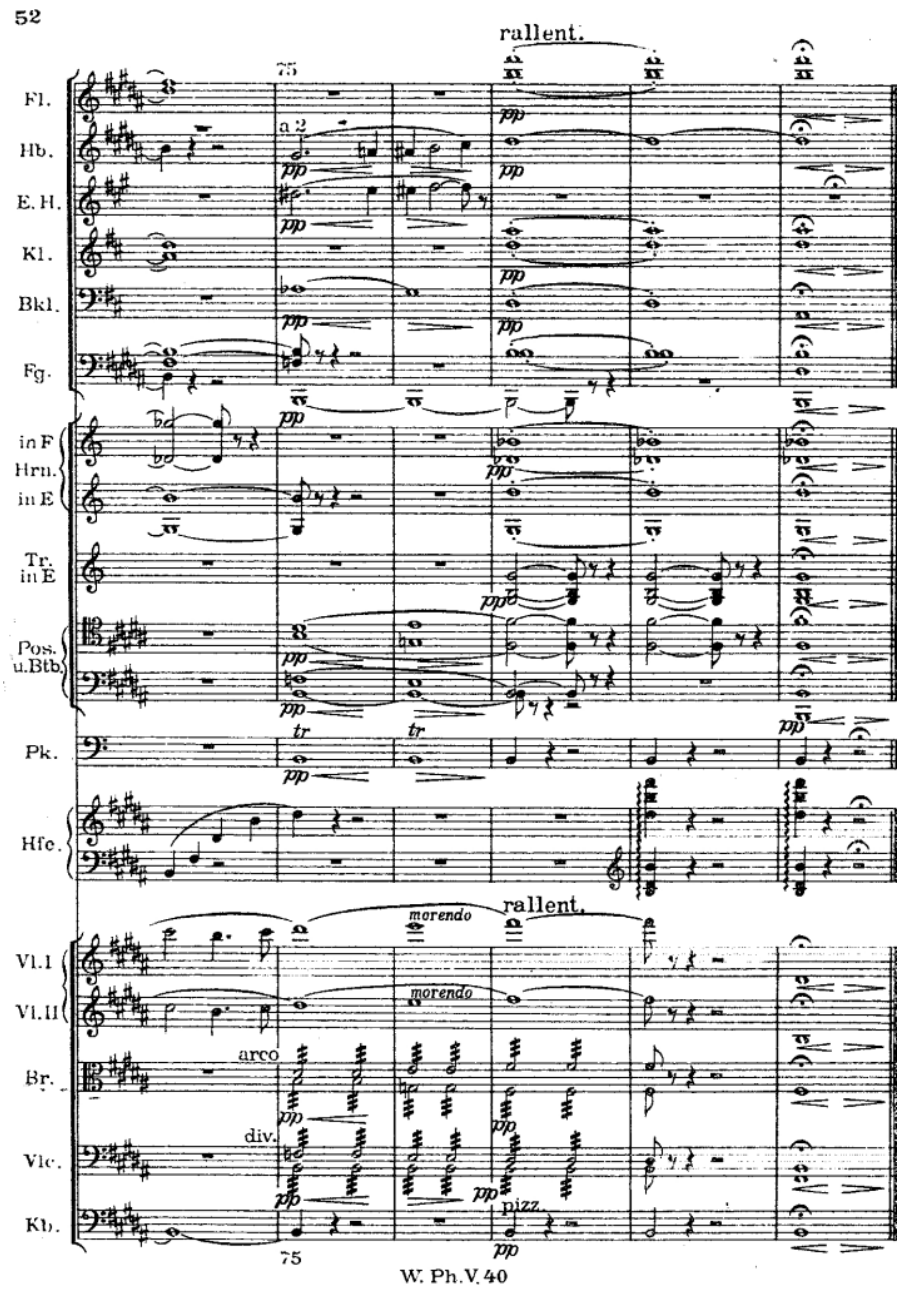

\section{$\mathrm{IV}_{3}^{4} \quad \mathrm{IV} \mathrm{II}^{6} \mathrm{I}$}

[exemplo 9 - final de Tristão e Isolda]

No final do Prélude, no c. 4 antes do fim, trompas e primeiros violinos apresentam o tema cromático descendente e ascendente, início do arabesco de flauta que abre a obra. Note-se a interessante harmonização em blocos de tríades maiores e menores. O que segue, no c. 3 antes do fim, é um acorde "tristão" sobre o quarto grau aumentado de Mi maior ( Lá $^{\#}, \mathrm{Mi}$, Sol ${ }^{\#}$ e Dó", configurando a sonoridade de Lá meio- 
diminuto) levando a um Mi maior, estrutura que é duplicada no c. 2 antes do fim, terminando finalmente em Mi maior.

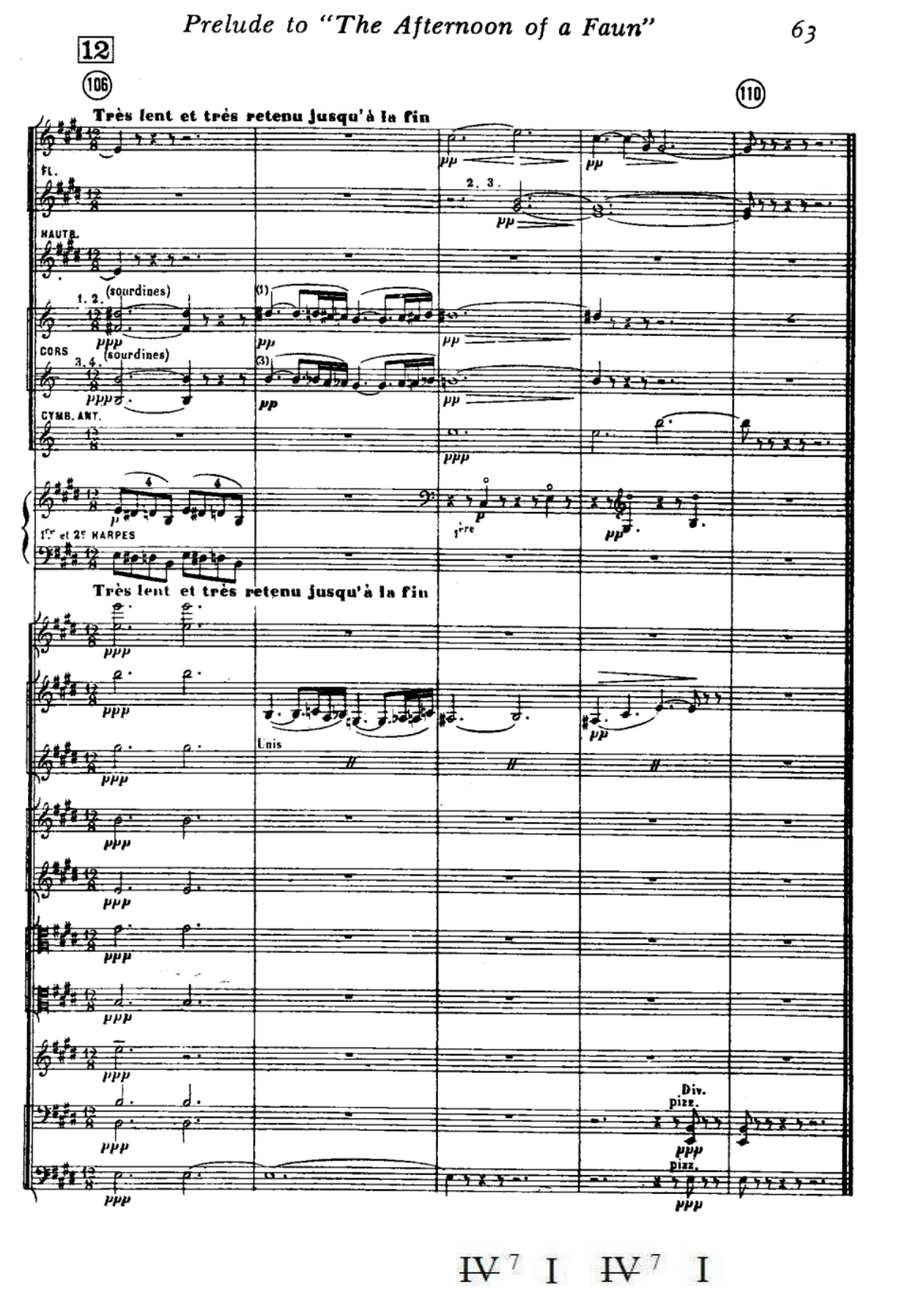

[exemplo 10 - final do Prélude]

Ambos os movimentos finais destas obras, assim, passam por suas sonoridades iniciais, o cromatismo e o acorde "tristão", agora sobre o quarto grau aumentado, levando à tônica maior conclusiva. 


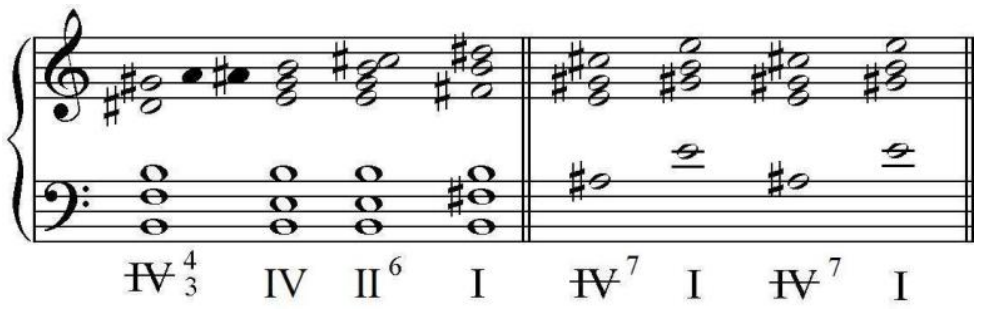

[exemplo 11 - final de Tristão e Isolda e do Prélude]

A homologia estrutural se manifesta nas duas pontas: o acorde "tristão", principal protagonista, abre e fecha as obras que fecham o passado e abrem o futuro.

O tempo é o que está em questão, já que ambas as obras têm a ver com a longa duração e apontam para o passado mítico. Tristan está ancorado na mitologia celta ${ }^{38}$, no arcaico sabor expressionista da correlação entre amor e morte. O Prélude, que nasce a partir de um quadro de Bucher que, visto pelo poeta Mallarmé, o inspira a escrever um poema sobre o fauno apaixonado, evocando o amor voluptuoso e o sofrimento na mitologia da Grécia clássica, base da composição de Debussy ${ }^{39}$. A partir deste passado longínquo e originário, musicado com cromatismo e constantes modulações no Tristan, e com arabescos e flutuações distantes da funcionalidade harmônica no Prélude, somos levados a pensar que ambas as obras, calcadas em arquétipos do Ocidente, abrem-se para o futuro, preludiando o tempo do pós-tonal.

Desta forma, as aberturas destas duas obras capitais apresentam uma homologia que leva a compreender a abertura do Prélude como uma espécie de sutil comentário ao Tristan, uma transformação poética de uma poderosa idéia wagneriana, logo nos primeiros momentos de uma obra de Debussy que vai brilhar na história como uma obra revolucionária, liberta das amarras do século XIX, portal do moderno. Procurei mostrar esta homologia nas dimensões da harmonia e da textura, concordando com BERRY sobre a importância da última na compreensão analítica das estruturas musicais (1987). O acorde "tristão" é mais que um simples acorde na ópera: é ele mesmo um motivo, talvez o leitmotiv mais importante em todo o drama, desde sua abertura até seu fechamento ${ }^{40}$. 0 Tristão no fauno é igualmente fundamental e, para além do Prélude, é constitutivo do próprio estilo de Debussy.

\footnotetext{
${ }^{38}$ Cf. BAILEY (1985).

${ }^{39}$ Ver AUSTIN, (1970).

${ }^{40}$ Como argumenta KURTH (1985, p. 195-196).

SIMPÓSIO DE PESQUISA EM MÚSICA 2007 - DEARTES/UFPR
}

DAPesquisa, Florianópolis, v.3 n.5, p.735-750, 2008. 
O "tristão" é hoje ainda uma sonoridade originária do espírito do final do século XIX e início do XX, brotando do processo de dissolução da harmonia em rumo ao póstonal. Neste período, cuja vertente vienense podemos chamar de "noite transfigurada do tonalismo", várias obras de Schoenberg e Berg empregam a "linguagem tristão", repletas de dissonâncias emancipadas ${ }^{41}$, acordes quartais e de tons inteiros ainda com funcionalidade harmônica (ALMADA, 2007). O acorde Tristão, entendido de forma flexível, como sonoridade, é igualmente um dos marcos estruturais deste período, parte da "nave harmônica" que se desprendeu da gravitação tonal (CORREA, 2006:21), sendo amplamente utilizado por Debussy e outros compositores da virada do século e posteriormente, como p. ex., Berg, na Lyrische Suite (WHITALL, 1999:188-9). A sonoridade Tristão se propaga ao longo de diversos repertórios musicais do século XX, incluindo a música brasileira ${ }^{42}$. Torna-se, assim, uma espécie de tópica, figura de retórica musical convencional de uma época ${ }^{43}$, carregando consigo marcas do modernismo e da weltanschauung franco-germânica do final do século XIX, como metáfora da essência do desejo e da ansiedade ${ }^{44}$. O "tristão no fauno", ecoando por todo o século XX, ainda hoje nos desafia a perceber de que mito profundo se origina.

\section{$\underline{\text { Referências Bibliográficas }}$}

ABBATE, Carolyn. 1981. "Tristan in the Composition of Pelleas,"19th Century Music vol. 5 no. 2: pp. 117141.

ALMADA, Carlos de L. "Emprego de elementos de origem não-tonal com finalidades funcionais na primeira Sinfonia de Câmara, Op. 9, de Arnold Schoenberg". Anais do XVIII Congresso da ANPPOM. São Paulo: UNESP, 2007.

AGAWU, V. Kofi. Playing with signs: a Semiotic Interpretation of Classic Music, Princeton: Princeton University Press, 1991.

AUSTIN, William W. Debussy - Prelude to "The Afternoon of a Faun". Norton Critical Scores. New York: W. W. W. Norton, 1970.

BAILEY, Robert (ed.). Wagner - Prelude and Transfiguration from Tristan and Isolde. Norton Critical Scores. New York: W. W. W. Norton, 1985.

BAUDELAIRE, Charles. "Lettre à Richard Wagner”. In Yves Hucher, La Musique. Paris: Librairie Larousse, 1977, p. 50-53.

BAUER, Harold. "Harold Bauer, His Book", In Roger Nichols (ed.) Debussy Remembered. Oregon:

Amadeus Press, 1992, p. 156-158.

BERRY, Wallace. Structural Functions in Music. New York: Dover Publications, 1987.

BONHEUR, Raymond. "Souvenirs et impressions d'un compagnon de jeunesse", In Roger Nichols (ed.)

Debussy Remembered. Oregon: Amadeus Press, 1992, p. 9-13.

BROWN. Matthew. Debussy's 'Iberia' - Studies in Musical Genesis and Structure. New York: Oxford University Press, 2003.

CODE, David J. Hearing Debussy Reading Mallarmé: Music après Wagner in the Prélude à l'après-midi d'un faune. Journal of the American Musicological Society, 2001, vol.54, no.3, pp.493-554.

COOK, Nicholas \& Everist, Mark. "Preface" In Nicholas Cook \& Mark Everist (eds.) Rethinking Music.

Oxford: Oxford University Press, 2001, p. iii-xii.

CORRÊA, Antenor Ferreira. Estruturações Harmônicas Pós-tonais. São Paulo: Unesp, 2006.

DEBUSSY, Claude. Monsieur Crochê e outros ensaios sobre música. Rio de Janeiro: Nova Fronteira, 1989 [1921].

DUDEQUE, Norton. "Schoenberg e a Função Tonal”. Revista Eletrônica de Musicologia. Vol. 2.1, DeArtes/UFPR, Outubro, 1997.

\footnotetext{
${ }^{41}$ SCHOENBERG (1989, p. 216). Ver DUDEQUE (2007).

${ }^{42}$ Ver o uso do acorde Tristão por Villa-Lobos em SALLES (2004).

${ }^{43}$ AGAWU (1991), PIEDADE (2007).

${ }^{44}$ WHITHALL (1995, p. 465).
}

SIMPÓSIO DE PESQUISA EM MÚSICA 2007 - DEARTES/UFPR 
DUDEQUE, Norton. Schoenberg: “Emancipação da dissonância, tonalidade expandida e variação progressiva em Frieden auf die Erde". Debates, 9, PPGM/CLA/UNIRIO, agosto, 2007, 7-34.

FURNESS, Raymond. "O impacto de Wagner na literatura", In Barry Millington (org.) Wagner: um compêndio. Rio de Janeiro: Jorge Zahar, 1995, pp. 465-468.

GILMAN, Lawrence. Debussy's Pelléas et Mélisande: a guide to the opera with musical examples from the score. New York: Schirmer, 1907. Disponível on-line em http://www.gutenberg.org.

GUIGUE, Didier. "Uma demonstração da reflexão debussysta sobre o pós-tonalismo". Revista Eletrônica de Musicologia, 4, DeArtes/UFPR, junho de 1999.

GUICHARD, Léon, La musique et les Lettres au temps du Wagnérisme. Paris: PUF, 1963.

HOLLOWAY, Robin. Debussy and Wagner. London: Eulenburg Books, 1979.

HOWAT, Roy. Debussy in Proportion: A Musical Analysis. Cambridge: Cambridge University Press, 1983.

KURTH, Ernst. "The Tristan Prelude", In Robert Bailey (ed.). Prelude and Transfiguration from Tristan and Isolde. Norton Critical Scores. New York: W. W. W. Norton, 1985, pp. 186-204.

KELLY, Barbara. "Debussy Parisian Afilliations", In Simon Trezise (ed.) The Cambridge Companion to Debussy. Cambridge: Cambridge University Press, 2003, p. 25-42.

LEROLLE, Henri. Carta a Ernest Chausson (25/02/1894), In Roger Nichols (ed.) Debussy Remembered. Oregon: Amadeus Press, 1992, p. 43-44.

LESTER, Joel. Analytical Approaches to 20th Century Music. New York: W.W. Norton \& Co., 1989. LORENZ, Alfred. "The Prelude", In Robert Bailey (ed.) Prelude and Transfiguration from Tristan and Isolde. Norton Critical Scores. New York: W. W. W. Norton, 1985, pp. 204-223.

MENEZES, Flo. Apoteose de Schoenberg. São Paulo: Ateliê Editorial, 2002.

MENEZES, Flo. Música Maximalista: ensaios sobre a música radical e especulativa. São Paulo: Editora da Unesp, 2006.

MITCHELL, William J. "The Tristan Prelude: techniques and structure”, In Robert Bailey (ed.). Prelude and Transfiguration from Tristan and Isolde. Norton Critical Scores. New York: W. W. W. Norton, 1985, pp.

242-267.

MORGAN, Robert P. Twentieth-Century Music: a history of musical style in modern Europe and America. New York and London: W. W. Norton, 1991.

NATTIEZ, Jean-Jacques. "Harmonia". Encicliopédia Einaudi, Vol. 3. Lisboa: Imprensa Nacional, 1984.

NATTIEZ, Jean Jacques. O Combate entre Cronos e Orfeu: ensaios de semiologia musical aplicada. São Paulo: Via Lettera, 2005.

PIEDADE, Acácio Tadeu de Camargo. “Expressão e sentido na música brasileira: retórica e análise musical”. Revista Eletrônica de Musicologia, Vol. XI, 2007.

PISTON, Walter. Harmony. London: Victor Golancz, 1994.

RUWET, Nicolas. "Notes sur la duplication dans l'Ouvre de Claude Debussy" In (do autor) Language, Musique, Poésie. Paris: Éditions du Seuil, 1972, pp. 70-99.

SALLES, Paulo de Tarso. "O Acorde Tristão em Villa-Lobos". Anais do VI Fórum do CLM. São Paulo: ECA/USP, 2004.

SALZER, Felix. Structural Hearing. New York: Dover, 1962.

SCHOENBERG, Arnold. Harmonia. São Paulo: EDUSP, 1999.

SCHOENBERG, Arnold. Funções Estruturais da Harmonia. São Paulo: Via Lettera, 2006.

SIMMS, Bryan R. Music of the Twentieth Century: style and structure. New York: Schirmer books, 1996. SMITH, Richard Langham. Motives and Symbols. In Roger Nichols \& Richard Langham Smith Debussy Pelléas et Mélisande. Cambridge: Cambridge University Press, 1989, pp. 78-106.

WHITTAL, Arnold. "O nascimento do modernismo: o impacto de Wagner na história da música, In Barry Millington (org.) Wagner: um compêndio. Rio de Janeiro: Jorge Zahar, 1995, pp. 461-465.

WHITTAL, Arnold. Musical Composition in the Twentieth Century. London: Oxford University Press, 1999.

Acácio Tadeu de Camargo Piedade possui graduação em Música (Composição) pela Universidade Estadual de Campinas (1985), mestrado e doutorado em Antropologia Social pela Universidade Federal de Santa Catarina (1997 e 2004). Professor do Departamento de Música e do Programa de PósGraduação em Música da Universidade do Estado de Santa Catarina, é coordenador dos grupos de pesquisa MUSICS/UDESC e MUSA/UFSC. Ministra disciplinas, pesquisa e orienta nas áreas de musicologia-etnomusicologia, teoria-análise e composição. 